\title{
Molecular Mimicry and Myasthenia Gravis \\ An Autoantigenic Site of the Acetylcholine Receptor $\alpha$-Subunit That Has Biologic Activity and Reacts Immunochemically with Herpes Simplex Virus
}

\author{
Peter L. Schwimmbeck, Thomas Dyrberg, Daniel B. Drachman, ${ }^{\star}$ and Michael B. A. Oldstone \\ Department of Immunology, Research Institute of Scripps Clinic, La Jolla, California 92037; and *Department of Neurology, \\ Johns Hopkins University School of Medicine, Baltimore, Maryland 21205
}

\begin{abstract}
The large majority of patients with the autoimmune disease myasthenia gravis characteristically have detectable antibodies against the acetylcholine receptor (AChR). We used synthetic peptides to identify antibodies in sera of myasthenia gravis patients reactive with the human acetycholine receptor (HuAChR) $\alpha$-subunit, residues 160-167. Affinity purification of these antibodies, using the HuAChR $\alpha$-subunit 157-170 peptide immobilized on thiopropyl-Sepharose, yielded IgG antibodies that bound to the native $\mathrm{AChR}$ and inhibited the binding of $\alpha$-bungarotoxin to the receptor. The HuAChR $\alpha$-subunit 160-167 peptide demonstrated specific immunological crossreactivity with a shared homologous domain on herpes simplex virus glycoprotein D, residues 286-293, by both binding and inhibition studies. Thus, $\mathrm{HuAChR} \alpha$-subunit, residues 160-167, elicits antibodies in myasthenic patients that binds to the native $\mathrm{AChR}$ protein and is capable of eliciting a biologic effect. Immunologic cross-reactivity of this "self" epitope with herpes simplex virus suggest that this virus may be associated with the initiation of some cases of myasthenia.
\end{abstract}

\section{Introduction}

The nicotinic acetylcholine receptor $(\mathrm{AChR})^{1}$ is composed of multiple subunits responsible for gating ion flow across membranes in response to binding of the neurotransmitter, acetylcholine (1). The actions of AChR antibodies, either experimentally induced or spontaneous, lead to the numerical reduction of available AChR and prevention of neuromuscular junction's ability to transmit signals from nerve fibers to muscle fibers; medically, the outcome is the autoimmune disease, myasthenia gravis (MG) (1-4). For molecular dissection of the ligand binding sites, synthetic peptides representing unique regions of the $\alpha$ subunit of AChR have been used in associa-

Please address reprint requests to Dr. Michael B. A. Oldstone, Department of Immunology, Research Institute of Scripps Clinic, 10666 North Torrey Pines Road, La Jolla, CA 92037.

Received for publication 19 September 1988 and in revised form 7 March 1989.

1. Abbreviations used in this paper: $\mathrm{AChR}$, acetylcholine receptor; $\alpha$-BuTx, $\alpha$-bungarotoxin; Gp, glycoprotein; HSV, herpes simplex virus; Hu, human; KLH, keyhole limpet hemocyanin; MG, myasthenia gravis.

\footnotetext{
J. Clin. Invest.

(c) The American Society for Clinical Investigation, Inc.

0021-9738/89/10/1174/07 \$2.00

Volume 84, October 1989, 1174-1180
}

tion with $\alpha$-bungarotoxin ( $\alpha$-BuTx) (5-9). These interactions also map accessible sites on AChR that bind antibodies.

We suggested the possibility that amino acid sequences shared between an infectious agent and a host protein (molecular mimicry) might enable the microbe to initiate an immunologic response that subsequently cross-reacts with the "self" determinant $(10,11)$, leading to an autoimmune disorder. Accumulated data indicate that for molecular mimicry to cause an autoimmune disease, three criteria must be met (11). First, amino acid sequences or conformational fit between the microbial agent and self protein must be different enough that immunologic tolerance does not occur and that an immune response is generated against the infectious agent. Secondly, these two structures must be sufficiently similar so that the immune response generated against the microbe cross-reacts with the self antigen. Third, the self determinant must be a "biologically active" part of the molecule.

Here we report the identification of a sequence in the $\alpha$ chain of human (Hu) AChR (amino acid residues 160-167) that shares an immunologically significant structural homology with herpes simplex virus (HSV) type 1 glycoprotein (Gp) D (amino acid residues 286-293). Sera from 6 of 40 patients with MG recognize this $\mathrm{HuAChR} \alpha$-subunit sequence. Antibodies purified from sera of two such MG patients using the corresponding synthesized AChR $\alpha$-subunit peptide and affinity chromatography were shown to cross-react to HSV. The one serum tested was found to block $\alpha$-BuTx binding to AChR both before and after affinity purification.

\section{Methods}

Patients. Sera of 40 patients with clinical MG were obtained from Johns Hopkins University School of Medicine (Dr. Drachman), Dr. D. Richman, University of Chicago, and Dr. R. Lisak, Wayne State Medical School, Detroit, MI. All sera were positive when tested for binding to native $A C h R$ by radioimmunoassay. Sera were stored in aliquots at $-20^{\circ} \mathrm{C}$ before use. Controls consisted of sera obtained from 40 randomly selected people not having MG.

Peptides and anti-peptide antibodies. Selected peptides of up to 17 amino acids were synthesized with an automatic peptide synthesizer (model 430A, Applied Biosystems, Inc., Foster City, CA) according to the solid-phase method as described (12). The peptides were cleaved from the polystyrene resin beads with hydrogen fluoride, extracted with $5 \%$ acetic acid, and lyophilized. Routinely before use, peptides were checked for purity by high-performance liquid chromatography with a reverse-phase $\mathrm{C} 18$ column. All peptides used in this study eluted from the column in a single peak containing at least $80 \%$ of the total. For immunization, we synthesized peptides with an additional cysteine as linker and two glycines as spacers at either the amino or carboxy terminus (13). The peptides were coupled at the cysteine to the carrier molecule, keyhole limpet hemocyanin (KLH) by using $M$-maleimidobenzoyl- $N$-hydroxysuccinimide ester as cross-linker $(13,14)$. Groups of three New Zealand white rabbits were prebled and immunized sub- 
cutaneously with $250 \mu \mathrm{g}$ of peptide-KLH mixed with complete Freund's adjuvant. Each animal received a second injection 2 wk later with the same amount of peptide in incomplete Freund's adjuvant. Again 2 wk later, each animal received an intraperitoneal booster injection of $250 \mu \mathrm{g}$ of peptide-KLH in an alum suspension, and after 1 wk the animals were bled, and sera were obtained and stored in aliquots at $-20^{\circ} \mathrm{C}$.

Immunochemical analysis. Binding of antibodies to a solid-phase antigen was determined by ELISA (15). Briefly, peptides in PBS were air-dried at $37^{\circ} \mathrm{C}$ onto polyvinyl chloride 96 -well plates ( $1 \mu \mathrm{g}$ per well). After blocking of free binding sites with ELISA diluent $(0.2 \%$ Tween $20,10 \%$ heat-inactivated FCS, and $0.5 \mathrm{mM}$ thimerosal in PBS), several dilutions of sera were added. After $90 \mathrm{~min}$ at room temperature, plates were washed three times, and affinity-purified horseradish peroxidase-labeled goat antibody to human IgG or rabbit IgG was added. After a further incubation of $90 \mathrm{~min}$, the plates were rewashed, and the substrate $\left(0.4 \mathrm{mg} / \mathrm{ml} O\right.$-phenylenediamine, $0.01 \% \mathrm{H}_{2} \mathrm{O}_{2}$ in citrate

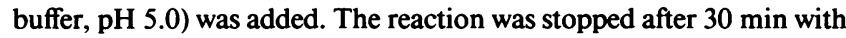
$4 \mathrm{M} \mathrm{H}_{2} \mathrm{SO}_{4}$. Samples were read at $492 \mathrm{~nm}$, with an automated ELISA scanner (Titertek Multiscan; Flow Laboratories, Inc., Inglewood, CA). Positive binding of MG sera was defined as a value greater than the mean \pm 2 SD of the values from 40 sera (controls) samples of individuals not having MG.

The binding to antigens in solution was assayed by immune precipitation. Briefly, to label peptides with ${ }^{125} I$, tyrosine was added at either the carboxyl or amino terminus of the synthesized peptide. The peptides were then iodinated with chloramine-T and dialyzed against PBS for $16 \mathrm{~h}$ to remove free iodine. For immunoprecipitation, ${ }^{125} \mathrm{I}$-peptide was incubated with serial dilutions of patient's sera in PBS for $1 \mathrm{~h}$ at $4^{\circ} \mathrm{C}$. Antigen-antibody complexes were precipitated using protein $\mathrm{A}$ on fixed Staphylococcus aureus (Pansorbin, Behring Diagnostics, La Jolla, CA). The pellet was washed extensively with PBS and counted in a gamma-counter (20/20 Series, Iso-Data, Inc., Rolling Meadows, IL).

For inhibition studies, aliquots of sera mixed with peptide at different concentrations were incubated for $1 \mathrm{~h}$ at room temperature with gentle shaking and assayed as described above.

Affinity purification. HuAChR $\alpha$-subunit, amino acids $157-170$, was synthesized with a cysteine added at the amino terminus with two glycines as spacers in between. $30 \mathrm{mg}$ of this peptide was coupled with $3 \mathrm{~g}$ of thiopropyl-Sepharose 6B (Pharmacia Fine Chemicals, Uppsala, Sweden) in $0.1 \mathrm{M}$ EDTA/0.5 M NaCl, $\mathrm{pH} 7.4$, for $1 \mathrm{~h}$ with constant end-over-end rotation. The remaining binding sites were blocked with mercaptoethanol $(0.9 \mathrm{mM}$ in $0.1 \mathrm{M}$ sodium citrate) at $\mathrm{pH} 4.5$ for $1 \mathrm{~h}$ at room temperature. This material was thoroughly washed with $50 \mathrm{mM}$ phosphate buffer at $\mathrm{pH} 7.2$ and $0.1 \mathrm{M}$ sodium citrate, $\mathrm{pH} 1.0$, transferred to a column (bed volume $10 \mathrm{ml}$ ), and equilibrated with $50 \mathrm{mM}$ phosphate buffer at pH 7.2. Immunoglobulins (Igs) from the sera were initially concentrated by ammonium sulfate precipitation and bound to the affinity column, and nonspecific (nonbinding) Igs removed using the equilibration buffer at neutral $\mathrm{pH}$. Specific antibodies were eluted using $0.1 \mathrm{M}$ citrate buffer at $\mathrm{pH} 1.0$ and rapidly neutralized with $1 \mathrm{M}$ Tris to $\mathrm{pH}$ 7.2. Collections were monitored for protein content at $280 \mathrm{~nm}$ (Pharmacia Fine Chemicals), and specificity was confirmed with a monospecific rabbit serum to human IgG $(13,16)$. In preliminary studies, tyrosine was added to the carboxyl terminus labeled with ${ }^{125} \mathrm{I}$ in order to monitor the amount of peptide bound to thiopropylSepharose. The amount of peptide immobilized on a $10-\mathrm{ml}$ column was $20 \mathrm{mg}$.

Determination of Ig concentration. Antibody eluted from the affinity column and specific for the AChR $\alpha$-subunit, amino acids 157-170, was concentrated by lyophilization. IgG concentration was measured by radial immunodiffusion assay (16) (Accra Assay, ICN Immuno Biologicals, Lisle, IL).

Detection of autoantibodies to AChR. Radioimmunoassays for antibodies binding to AChR were performed according to a modification of methods previously described (17), using AChR extracted from muscle of amputated human limb. The concentration of antibody was calculated from the amount of ${ }^{125} \mathrm{I}-\alpha-\mathrm{BuTx}$-labeled $\mathrm{AChR}$ precipitated in the linear portion of the dilution curve, and was expressed as moles of $\alpha$-BuTx binding sites $\times 10^{-9}$ precipitated per liter of serum.

Blockade of $A C h R$. Rat skeletal muscle (myotube) cultures were prepared as previously described (18). All procedures were carried out at $4^{\circ} \mathrm{C}$ to maximize the blocking effect of the antibodies and to eliminate degradation of $\mathrm{AChRs}$ by the muscle cells. Medium containing serum ( $20 \%$ by volume, or an equivalent amount of affinity-purified IgG reconstituted to its original volume) was incubated with sets of five replicate cultures for $18 \mathrm{~h}$. After the cultures were thoroughly rinsed, the remaining unblocked AChRs were labeled by incubation with of ${ }^{125} \mathrm{I}-\alpha$-BuTx $\left(12.5 \times 10^{-11} \mathrm{M}\right)$ for $4 \mathrm{~h}$ at $4^{\circ} \mathrm{C}$. The cultures were repeatedly rinsed to remove unbound ${ }^{125} \mathrm{I}-\alpha-\mathrm{BuTx}$, extracted with $2 \%$ Triton $\mathrm{X}-100$ in PBS, and the radioactivity in the extracts was counted. The mean number of $\alpha$-BuTx binding sites for each set of cultures was calculated from the bound radioactivity (typically $\sim 6.0 \times 10^{-13} \mathrm{~mol}$ of $\alpha$-BuTx binding sites per 35-mm dish). Blockade of $\alpha$-BuTx binding sites induced by MG antibodies was calculated by subtracting the mean number of $\alpha$-BuTx binding sites in cultures from the mean number of $\alpha$-BuTx binding sites in cultures treated with control serum. Blockade was expressed as moles $\times 10^{-13}$ of $\alpha$-BuTx binding sites lost.

Immunofluorescent staining. Binding of antibodies to HSV was assayed by using HSV-infected cells and a FITC-labeled second antibody to human IgG. Briefly, baby hamster kidney cells were infected with HSV 1, strain KOS, at a multiplicity of infection of 3 and seeded on coverslips in DME, 7\% heat-inactivated FCS, $2 \mathrm{mM}$ glutamine, and $50 \mathrm{mM}$ penicillin/streptomycin. After $16 \mathrm{~h}$ the cells were fixed with ethanol/ether and incubated with 10\% normal rat serum in PBS for $1 \mathrm{~h}$ to block nonspecific binding of human Ig to the Fc receptors. The coverslips were rinsed, then test sera or affinity-purified antibodies were added before a 30-min incubation at room temperature. The coverslips were washed with PBS and FITC-labeled, affinity-purified goat antibody to human IgG (Boehringer Mannheim Biochemicals, Indianapolis, IN) was added. Specificity was monitored using a known monospecific antibody to HSV as a positive control, a monospecific antibody to human cytomegalovirus and a serum of a person negative for HSV as a negative control $(19,20)$.

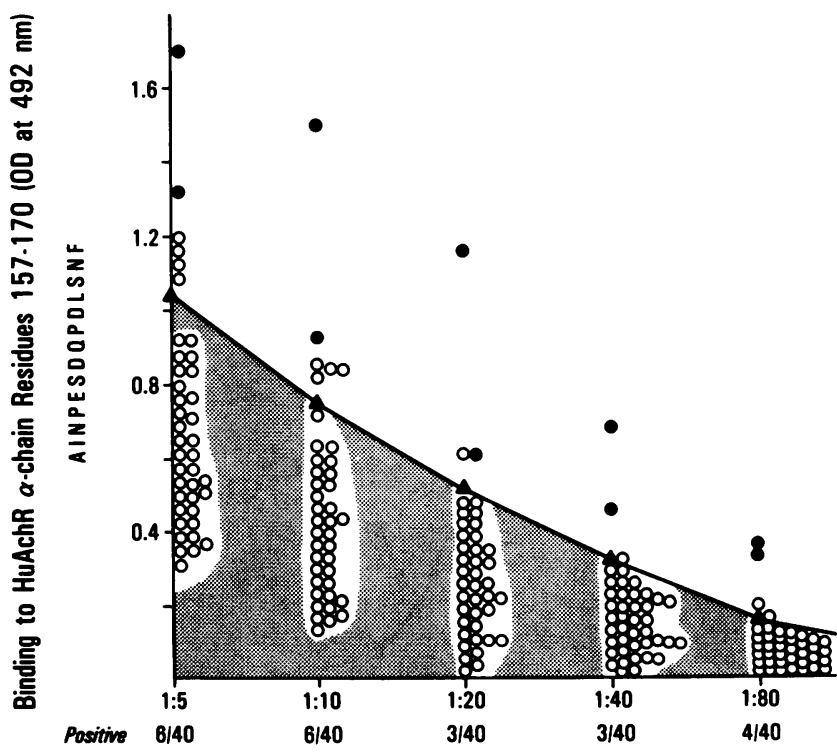

Figure 1. Binding of sera from MG patients to HuAChR $\alpha$-subunit, amino acids 157-170. Circles represent the values of sera from 40 individual MG patients. Six of these MG patients has values $>2$ SD above the mean of values from non-MG controls (see below). The results for patients MG6 and MG34, used in subsequent studies are marked (๑). The background (shaded area) represents the mean value plus 2 SD for serum collected from 40 controls without MG. 


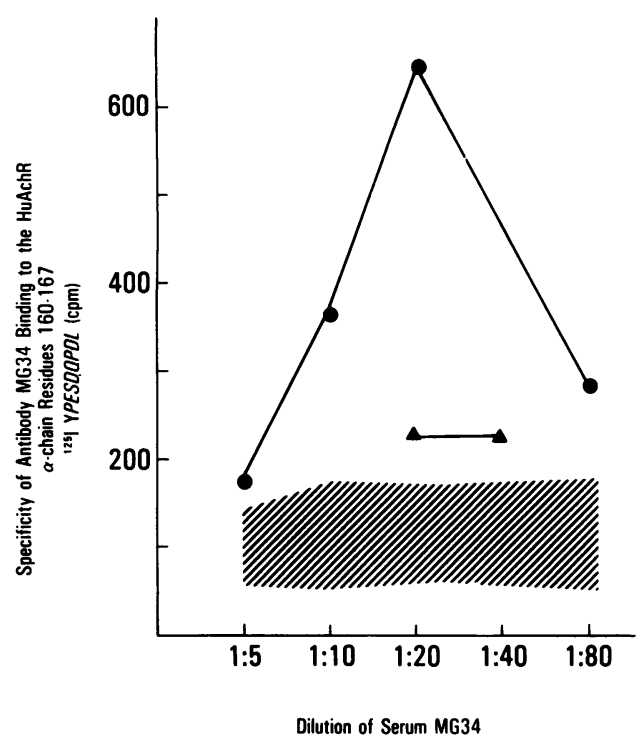

Figure 2. Binding of antibody from patient MG34 to HuAChR $\alpha$-subunit, amino acids $160-167$. The serum was incubated with ${ }^{125} \mathrm{I}$ YPESDQPDL with tyrosine added to the proline (position 160). The number of ${ }^{125}$ I counts bound by the antibody and precipitated with Staphylococcus aureus protein A is shown for several serum dilutions (๑). The binding was immunologically specific as $50 \mu \mathrm{g}$ of cold peptide $(\Delta)$ competitively blocked the binding of MG34 sera to ${ }^{125} \mathrm{I}-\mathrm{la}$ beled peptide. Sera from 40 nonmyasthenic controls failed to precipitate the ${ }^{125}$ I-labeled peptide (shaded area).

\section{Results}

Presence of autoantibodies to the HuAChR $\alpha$-subunit, residues 160-167. Sera from 40 patients with MG were tested in ELISA for binding to a peptide representing the HuAChR $\alpha$-subunit, amino acid residues 157-170. As shown in Fig. 1, 6 of 40 sera (15\%) bound 2 or more SD above the mean of values for 40 nonmyasthenic controls. Similarly, using a radioimmune precipitation assay, these six sera positive by ELISA also bound to a ${ }^{125} \mathrm{I}$-labeled peptide of $\mathrm{HuAChR} \alpha$-subunit, residues $160-167$, to which tyrosine had been added at the carboxyl end ( ${ }^{125}$ I-YPESDQPDL). Data from one such patient, MG34, are shown in Fig. 2. The binding of antibody was specific, since it was completely inhibited by the addition of $50 \mu \mathrm{g}$ of the unlabeled peptide (Fig. 2). Results were similar with the other five sera. Owing to the limitation of materials, the remaining experiments were performed with sera from patients MG6 and MG34.

Affinity purification of antibodies reactive to $H u A C h R$. Antibodies from the sera of patients MG6 and MG34 were isolated on a thiopropyl-Sepharose column to which HuAChR $\alpha$-subunit, peptide $157-170$ was coupled (Fig. 3, peak $B$ ). The materials eluted in peak $B$ contained $>98 \%$ of antibody specific to $\mathrm{HuAChR} \alpha$-subunit, amino acids 157-170. Peak $A$ (Fig. 3) contained the vast majority of total Ig in the sera but, $<2 \%$ of the antibody reactive to $\mathrm{HuAChR} \alpha$-subunit, peptide amino acids $157-170$.

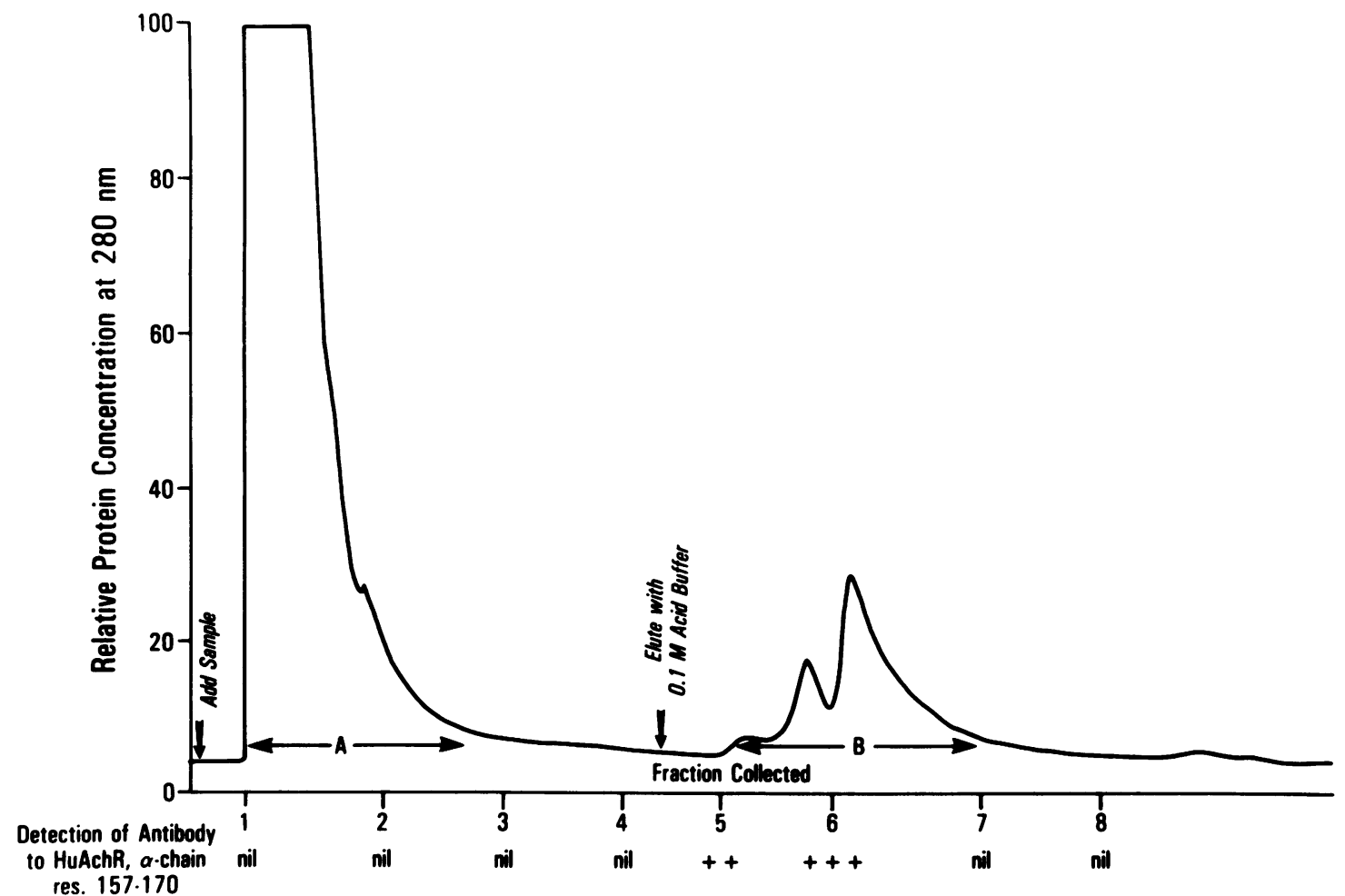

Figure 3. Utilization of affinity chromatography to isolate antibody from MG No. 34 serum that binds to HuAChR $\alpha$-subunit, amino acids 157-170. A 10-ml column containing $20 \mathrm{mg}$ of the peptide C-G-G-AINPESDQPDLSNF was bound to thiopropyl-Sepharose. The flow through peak $A$ represented the majority of the protein and Ig, but $<2 \%$ of antibody to HuAChR $\alpha$-subunit, amino acids $157-170$. Upon addition of $0.1 \mathrm{M}$ sodium citrate, pH 1.0, antibodies to HuAChR $\alpha$-subunit, amino acids $157-170(>98 \%)$ were eluted (peak $B$ ) from the column. 
Affinity-purified autoantibodies bind to native AChR and have biologic activity. Serum from MG6 and MG34 bound native $\mathrm{HuAChR}$ in a radioimmunoassay (Table I). The affinity-purified antibodies (peak $B$, Fig. 3) from both patients were concentrated by lyophilization and then reconstituted by dilution to their original serum volume. Radioimmunoassays showed that the affinity-purified IgG from serum 34 retained about $40 \%$ of its binding to native AChR (see Table I). The affinity-purified preparation from serum 6 had significant AChR-binding antibody (23\%).

Enough material was available to test blockade of $\alpha$-BuTx binding for serum and affinity-purified Ig from serum 6 . This purified preparation retained $\sim 75 \%$ of its ability to block $\alpha$-BuTx binding sites $(P<0.02$ as compared with controls, Table I). Sera from which these antibodies were isolated blocked, to a greater extent, the binding of ${ }^{125} \mathrm{I}-\alpha$-BuTx to native AChR than did the isolated peptide antibody, indicating the likely presence of additional antibodies able to bind to other exposed amino acid residues on the AChR.

Conserved amino acid sequences and immunologic crossreactivity between HuAChR $\alpha$-subunit, amino acids 160-170, and HSV-1 GpD sequences. Computer analysis demonstrated a number of amino acids shared between HuAChR $\alpha$-subunit, residues $160-167$, and HSV-1 GpD, residues 286-293 (10). To test the immunochemical significance of this observation, a peptide was synthesized containing HuAChR $\alpha$-subunit, amino acids 160-167, with C-G-G added to terminal amino acid 160 . This peptide was coupled to $\mathrm{KLH}$ and the mixture used to immunize rabbits and raise high-titered antibody (titer $>1 / 160,000$ when tested against the immunizing peptide). As Fig. 4 illustrates, this antibody showed immunologic cross-reactivity between HuAChR amino acids 160-167 and HSV-1 GpD sequences 286-293, but not to an irrelevant sequence HuAChR, residues 386-393. Further, HSV-1 GpD peptide 286-293 competitively inhibited the binding of antibody made against HuAChR $\alpha$-subunit, amino acids $160-167$, to its corresponding AChR peptide (Fig. 5). In contrast, an unrelated peptide from a different region of the HuAChR $\alpha$-subunit, residues 386-393, failed to inhibit peptide-antibody binding. Hence, HSV GpD amino acids 286-293 showed im-

Table I. Autoantibodies to HuAChR $\alpha$-Subunit Residues 157-170 Isolated from Myasthenia Patients Bind Native AChR and Block Binding of $\alpha$-Bungarotoxin

\begin{tabular}{|c|c|c|c|}
\hline & & \multicolumn{2}{|c|}{$\begin{array}{c}\text { Reaction of antibodies from MG patients } \\
\text { with native } A C h R\end{array}$} \\
\hline \multicolumn{2}{|c|}{ Antibodies from MG patients } & \multirow[b]{2}{*}{ Binding to $\mathrm{AChR}^{\ddagger}$} & \multirow{2}{*}{$\begin{array}{c}\text { Blockade of binding } \\
\text { to } \mathrm{AChR}^{\delta}\end{array}$} \\
\hline Source & State* & & \\
\hline MG34 & Serum & $\begin{array}{l}\times 10^{-9} \mathrm{M} \\
\quad 7.5\end{array}$ & $\begin{array}{l}m o l \times 10^{-13} \\
\mathrm{ND}\end{array}$ \\
\hline MG6 & Serum & 61.09 & $2.08 \pm 0.24^{\prime \prime}$ \\
\hline MG34 & Affinity purified & 3.0 & ND \\
\hline MG6 & Affinity purified & 13.89 & $1.55 \pm 0.25^{\prime}$ \\
\hline \multicolumn{4}{|c|}{$\begin{array}{l}\text { * Antibodies were affinity purified as stated in Methods, reconsti- } \\
\text { tuted with PBS to the same volume as the serum from which they } \\
\text { originated, and assayed at that concentration. } \\
{ }^{\ddagger} \text { Binding was measured by radioimmunoassay using human AChR } \\
\text { (see Methods for details). } \\
\text { § See Methods for details. } \\
\text { " } P<0.01 \text {, when compared with control sera. } \\
\text { "Significant blockade at } P<0.02 \text {, when compared with control sera }\end{array}$} \\
\hline
\end{tabular}

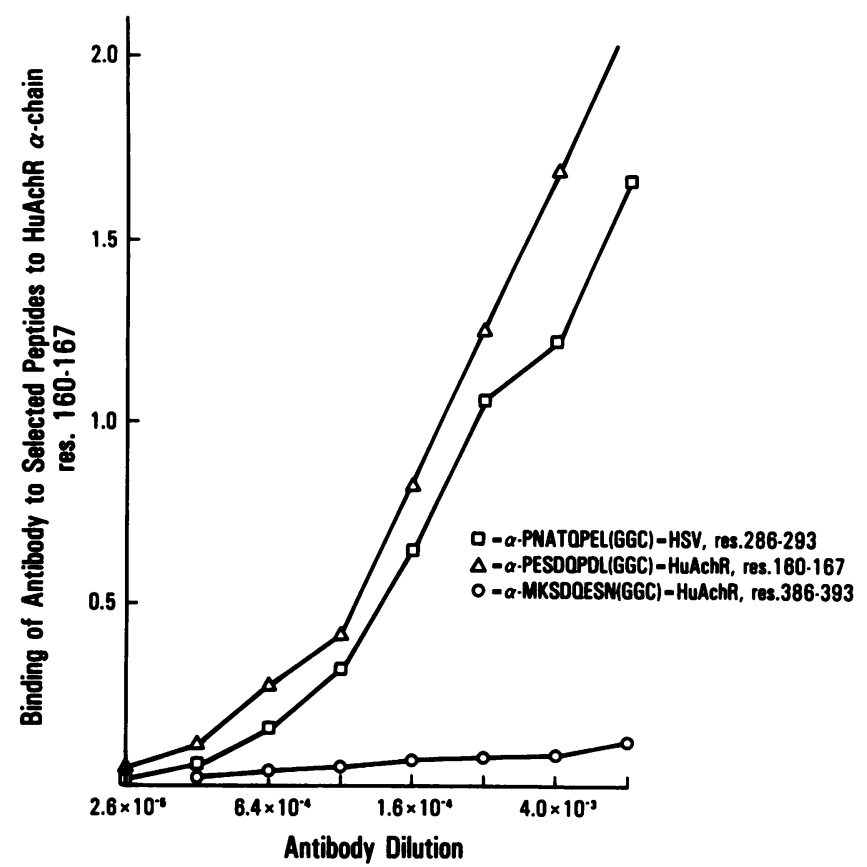

Figure 4. Immunologic cross-reactivity of rabbit antibodies raised against peptides HuAChR amino acids 160-167 and other peptides. Antibodies against the various peptides were used in the dilutions shown on the $x$-axis. The $y$-axis records the binding to HuAChR $\alpha$ subunit, amino acids $160-167$ as measured at $492 \mathrm{~nm}$.

munologically significant sequence homology to the biologically active site of HuAChR $\alpha$-subunit sequence 160-167.

Reactivity of antibodies to HuAChR $\alpha$-subunit, amino acids 157-170, with $H S V$. The final set of experiments analyzed the binding of antibodies to HuAChR $\alpha$-subunit, amino acids 157-170, from patient MG34 to HSV native protein in infected cells. The autoantibodies present in untreated serum of patient MG34 (Fig. $6 \mathrm{~A}$ ) and antibodies obtained by affinity

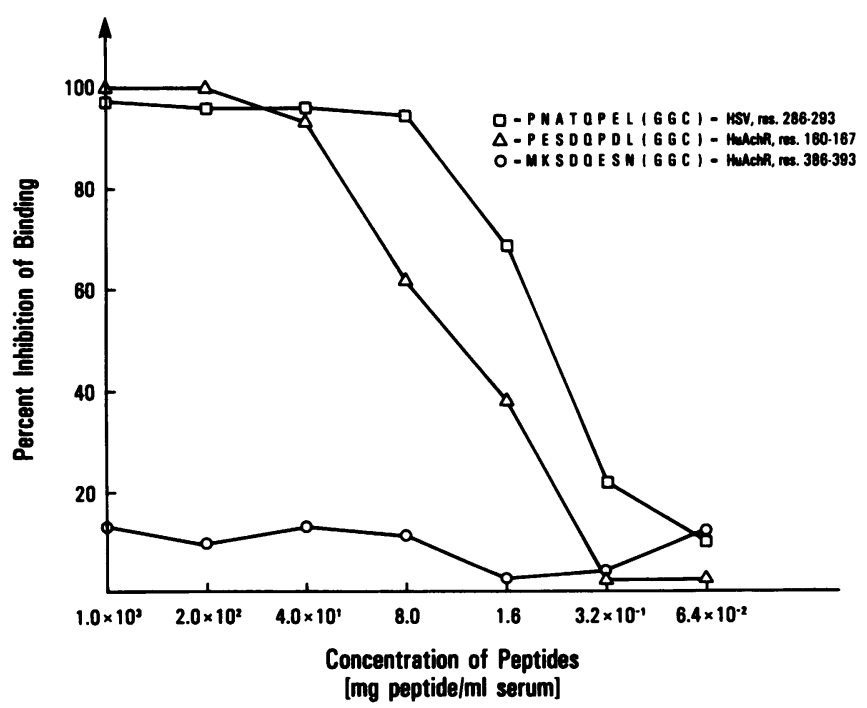

Figure 5. Specificity of immunologic cross-reactivity between HuAChR $\alpha$-chain amino acids $160-167$ and HSV-1 GpD amino acids 286-293. Increasing concentrations of the three peptides were added in an attempt to block the binding of HuAChR $\alpha$-subunit, residues $160-167$, to the immunizing peptide, as given on the $x$-axis. The resulting inhibition is recorded on the $y$-axis. 

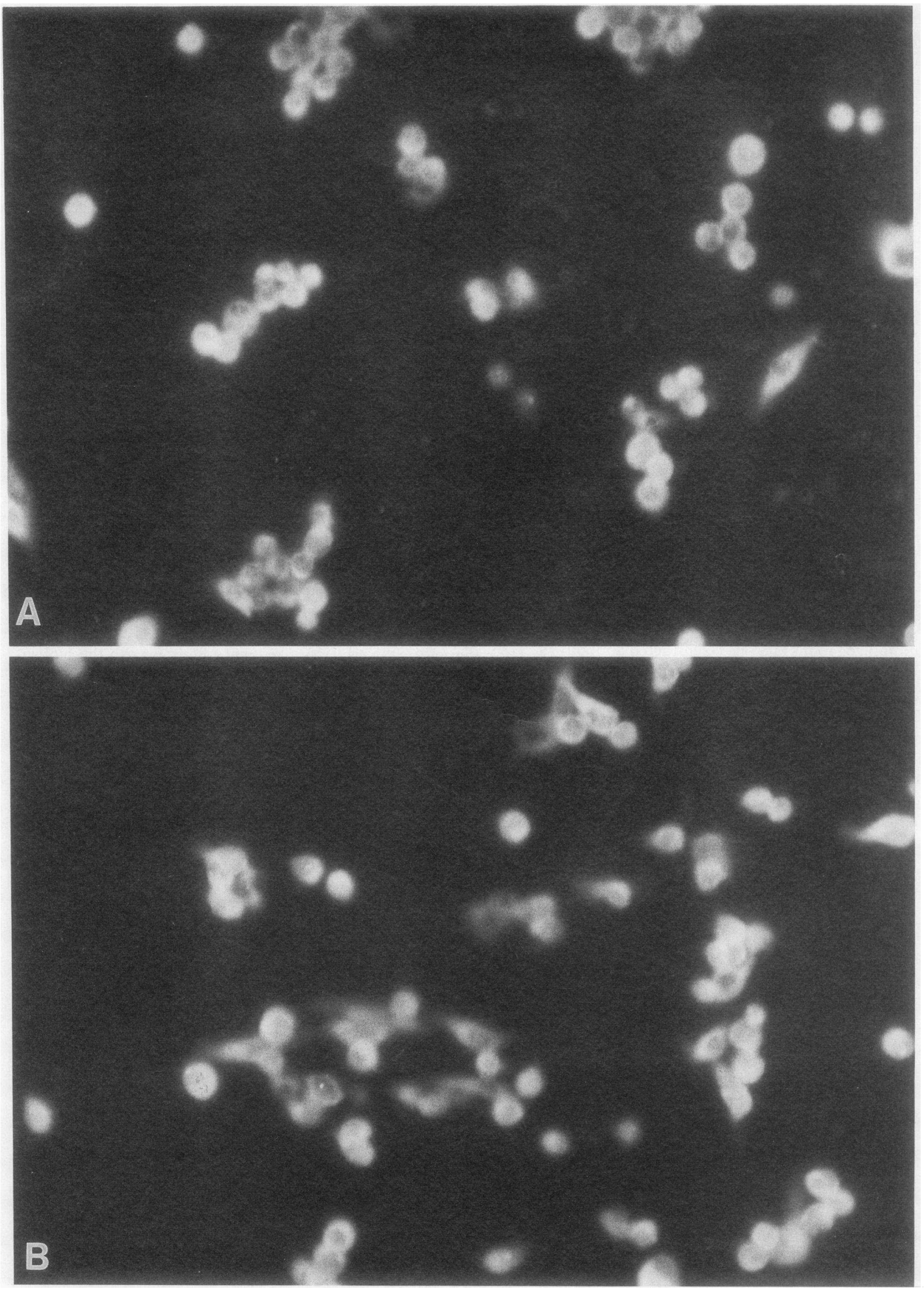

Figure 6. Antibodies to HuAChR $\alpha$-subunit, amino acids 160-167 obtained from patient MG34 binds to HSV-infected cells. Antibodies from untreated MG34 sera $(A)$ or the corresponding affinity-purified antibodies $(B)$ (see Fig. 3 for affinity purification data) were used along with FITC-conjugated goat antibody to human IgG. 
purification with $\mathrm{HuAChR}$, residues $157-170$ (Fig. $6 \mathrm{~B}$ ), both stained HSV-infected cells. Similar results were obtained with serum 6. In contrast, these antibodies failed to stain similar cells infected with an indifferent viruses, human cytomegalovirus and lymphocytic choriomeningitis virus. Additionally, sera from healthy individuals (non-MG patients) who were negative for HSV-1 failed to stain HSV-infected cells.

\section{Discussion}

Here we document molecular mimicry between $\mathrm{HuAChR}$ and a human pathogen, HSV, and present data suggesting a possible connection between this observation and MG. First, among our findings is that antibody to HuAChR $\alpha$-subunit, residues 160-167, was made in 6 of 40 patients with MG (15\% of the 40 individuals studied), and this antibody is accessible to react with $\mathrm{AChR}$ on muscle cells. Secondly, the antibody has biologic activity evident as binding to AChR. Thirdly, there is sequence sharing between HuAChR $\alpha$-subunit, amino acids 160-167, and HSV-1 GpD amino acids 286-293, and these two dissimilar proteins show specific immunologic cross-reactivity.

Six of 40 patients with MG tested here had autoantibodies to HuAChR $\alpha$-subunit, residues 160-167. Although the AChR $\alpha$-subunit's identity as the immunodominant subunit of the receptor has been noted (21-24), only recently by using synthetic peptides (5-9) have specific functional domains been identified. Such studies showed that residues around 192-193 of the AChR $\alpha$-subunit from Torpedo californica include an $\alpha$-BuTx binding site (5-9), although the same sequence from the HuAChR is not reactive with $\alpha$-BuTx (6). Our studies, using affinity-purified autoantibodies to $\mathrm{HuAChR} \alpha$-subunit 157-170 from MG patient sera, show that this antibody significantly blocked the binding of $\alpha$-BuTx to cultured rat muscle cells (myotubes). Thus, it is likely that either this region is in close proximity to the toxin binding site or binding of antibody to this region conformationally alters the neighboring $\alpha$-BuTx binding site. These issues are currently being evaluated with physicochemical and high-resolution electron microscopic techniques (Unwin, N., P. Schwimmbeck, and M. B. A. Oldstone, unpublished data). Nevertheless, because these autoantibodies interfere with the ligand binding site of $\mathrm{HuAChR}$, they may likely possess pathological significance.

HuAChR $\alpha$-subunit, amino acids $157-170$, is not located in the so-called "main immunogenic region." That region is composed of amino acids 6-85 or 46-127 of AChR (21-24), an area to which the majority of patients with MG have antibodies and which is believed to be highly conformationally dependent while including noncontiguous amino acid sequences of the AChR $\alpha$-subunit (8). The six MG patients we studied all had antibodies against $\mathrm{HuAChR} \alpha$-subunit 157-170 and thus responded to determinants outside of this region. This indicates the presence of immunoreactive sites outside the main immunodominant region (21). In addition, these six individuals also had antibodies against other epitopes of the HuAChR. Hence, autoantibodies present in one patient are likely directed to multiple epitopes on the AChR.

The structure and location of the autoimmune epitope(s) in the native molecule is important with respect to its recognition by immune reactants. Hydrophilic sequences are more likely to be exposed and reactive with antibodies than hydrophobic domains, although recent studies using synthetic peptides and viruses have shown that antibodies can also react with hydrophobic antigenic sequences (25-27). Structural analysis of HuAChR $\alpha$-subunit, residues $157-170(10,28,29)$, showed that this domain is hydrophilic, thus likely to be exposed on the protein surface. Furthermore, the predicted secondary structure (30) of HuAChR 157-170 places it at a loop of the molecule, since the sequence contains two prolines, giving it a high $\beta$-turn potential and thus a probable exposed location.

Relatively little is known about the etiology of MG, although its pathogenesis is well understood and its autoantigens have been characterized $(1-4,21)$. We have identified a sequence homology between HuAChR $\alpha$-chain 160-167 and HSV-1 GpD residues 286-293 and shown immunochemically that the four shared amino acids are sufficient to induce significant cross-reactivity against both peptides and native proteins. Presumably, the unshared amino acids are conserved substitutions and not located at the binding site. Indeed, elsewhere we have utilized single amino acid substitutions to map the constraints of the binding site and experimentally prove this point (Dyrberg, T., manuscript submitted). Perhaps an immune response generated against a microbe like HSV could cross-react with host AChR. This could result in a virus induced autoimmune response leading to autoimmune disease. The diseasecausing microbe may be cleared by the initial immune response and thus be difficult to detect or could persist in a latent state. Subsequent reactivation would enable the microbe to serve as a potent modulator of the autoimmune disease by antigenic stimulation. Direct evidence to prove that this or any human autoimmune disorder is caused by such a scenario will be difficult to obtain. So far the few attempts made to identify virus by study of the thymus gland of patients with recent onset MG have yielded negative results $(31,32)$ although it is unlikely that this tissue would be a source for detection of a virus like HSV. The ability of molecular mimicry to cause disease has been shown experimentally $(33,34)$. Others have documented immunologic cross-reactivity with bacteria and AChR (35), further suggesting that several microbial agents (35-37) may play a role in MG.

The concept of molecular mimicry provides a useful strategy for identifying possible etiologic agents of several wellcharacterized human diseases (reviewed by Dyrberg and Oldstone [10]). Associations have been established between specific antigenic determinants of Streptococcus and rheumatic heart disease $(38,39)$, Klebsiella pneumoniae nitrogenase and ankylosing spondylitis/Reiter's syndrome/HLA-B27 (15), and adenovirus 12 Elb protein and celiac disease (40). Recent observations (reviewed in reference 10) of sequence homology among several important host determinants such as myelin basic protein, proteolipid protein of myelin, brain specific protein, insulin receptor, coagulation proteins, etc., with a variety of viruses and bacteria associated with demyelination, dementia, diabetes, and hemorragic syndromes, respectively, suggest that this strategy may both serve as a guide and be of value in exploring the etiologic agents of these and other diseases. However, one should keep in mind that current technology allows probing for shared linear sequences of amino acids. Conformationally determined epitopes also likely to be of importance, are not yet accessible for analysis.

\section{Acknowledgments}

The authors thank Jon Lindstrom, Salk Institute, La Jolla for helpful discussions and review of the manuscript. We acknowledge the tech- 
nical assistance of Nina Bland and manuscript preparation by Diane Nolin and Phyllis Minick.

This work was supported by grants AI-07007 and NS-12428 from the National Institutes of Health. Dr. Schwimmbeck was a recipient of a grant from the Deutsche Forschungsgemeinschaft (DFG).

\section{References}

1. McCarthy, M. P., J. P. Earnest, E. F. Young, S. Choe, and R. M. Stroud. 1986. The molecular neurobiology of the acetylcholine receptor. Annu. Rev. Neurosci. 9:383-413.

2. Lindstrom, J., D. Shelton, and Y. Fujii. 1988. Myasthenia gravis. Adv. Immunol. 42:233-283.

3. Drachman, D. 1978. Myasthenia gravis. N. Engl. J. Med. 298:136-186.

4. Drachman, D., editor. 1978. Myasthenia gravis, biology and treatment. Ann. NY Acad. Sci. 505:1-914.

5. Neumann, D., D. Barchan, A. Safran, J. M. Gershoni, and S. Fuchs. 1986. Mapping of the $\alpha$-bungarotoxin binding site within the $\alpha$ subunit in the acetylcholine receptor. Proc. Natl. Acad. Sci. USA. 83:3008-3011.

6. Mulac-Jericevic, B., and M. Atassi. 1986. Segment $\alpha 182-198$ of Torpedo californica acetylcholine receptor contains a second toxin binding region and binds anti-receptor antibodies. FEBS (Fed. Eur. Biochem. Soc.) 199:68-74.

7. Atassi, M. Z., B. Mulac-Jericevic, T. Yokoi, and T. Manshouni. 1987. Localization of the functional sites on the $\alpha$-chain of acetylcholine receptor. Fed. Proc. 46:2538-2547.

8. Ralston, S., V. Sarim, H. Thanh, J. Rivcer, J. Fox, and J. Lindstrom. 1987. Synthetic peptides used to locate the $\alpha$-bungarotoxin binding site and immunogenic regions on $\alpha$ subunits of the nicotinic acetylcholine receptor. Biochemistry. 26:3261-3266.

9. Fuchs, S., B. Neumann, A. Saffran, M. Souroujon, D. Barchan, M. Fritdkin, J. M., Gershoni, R. Montegazza, and S. Pizzighella. 1987. Synthetic peptides and their antibodies in the analysis of the acetylcholine receptor. Ann. NY Acad. Sci. 505:256-270.

10. Dyrberg, T., and M. B. A. Oldstone. 1986. Peptides as probes to study molecular mimicry and virus induced autoimmunity. Curr. Top. Microbiol. Immunol. 130:25-37.

11. Oldstone, M. B. A. 1987. Molecular mimicry and autoimmune disease. Cell. 50:819-820.

12. Merrifield, R. B. 1969. Solid-phase peptide synthesis. Adv. Enzymol. 32:221-296.

13. Dyrberg, T., and M. B. A. Oldstone. 1986. Peptides as antigens: importance of orientation. J. Exp. Med. 164:1344-1349.

14. Liu, F. T., M. Zinnecker, T. Hanaoka, and D. H. Katz. 1979. New procedures for preparation and isolation of conjugates of proteins and a synthetic copolymer of D-amino acids and immunochemical characterization of such conjugates. Biochemistry. 18:690-697.

15. Schwimmbeck, P. L., D. T. Y. Yu, and M. B. A. Oldstone. 1987. Autoantibodies to HLA B27 in the sera of HLA B27 patients with ankylosing spondylitis and Reiter's syndrome: molecular mimicry with Klebsiella pneumoniae as potential mechanism of autoimmune disease. J. Exp. Med. 166:173-181.

16. Mancini, G., A. O. Carbonara, and J. F. Heremans. 1965. Immunochemical quantitations of antigens by single radial immunodiffusion. Immunochemistry. 2:235-254.

17. Bray, J. J., and D. B. Drachman. 1987. Binding affinities of anti-acetylcholine receptor autoantibodies in myasthenia gravis. $J$. Immunol. 128:105-110.

18. Drachman, D. B., R. N. Adams, L. F. Josifek, and S. G. Self. 1982. Functional activities of autoantibodies to acetylcholine receptors and the clinical severity of myasthenia gravis. N. Engl. J. Med. 207:769-775.

19. Rice, G. P., R. D. Schrier, and M. B. A. Oldstone. 1984. Cytomegalovirus infects human lymphocytes and monocytes: virus expression is restricted to immediate-early gene products. Proc. Natl. Acad. Sci. USA. 81:6134-6138.
20. Goldstein, L. C., L. Corey, J. K. McDougall, E. Tolentino, and R. C. Nowinski. 1983. Monoclonal antibodies to herpes simplex viruses: use in antigenic typing and rapid diagnosis. J. Infect. Dis. 147:829-837.

21. Tzartos S. J., and J. M. Lindstrom. 1980. Monoclonal antibodies used to probe acetylcholine receptor structure: localization of the main immunogenic region and detection of similarities between subunits. Proc. Natl. Acad. Sci. USA. 77:755-759.

22. Noda, M., Y. Furutzni, H. Takahashi, M. Toyosato, T. Tanabe, S. Simizu, S. Kikyotani, T. Kayano, T. Hirose, S. Inayama, and S. Numa. 1983. Cloning and sequence analysis of calf cDNA and human genomic DNA encoding $\alpha$ subunit precursor of muscle acetylcholine receptor. Nature (Lond.). 305:818-823.

23. Barkas, T., A. Mauron, B. Roth, C. Alliod, S. Trantos, and M. Ballivet. 1987. Mapping the main immunogenic region and toxin binding site of the nicotinic acetycholine receptor. Science (Wash. DC). 235:77-80.

24. Ratnam, M., P. B. Sargent, V. Sarin, J. L. Fox, D. Le Nguyen, J. Rivier, M. Criado, and J. Lindstrom. 1986. Location of antigenic determinants on primary sequences of subunits of nicotinic acetycholine receptor by peptide mapping. Biochemistry. 25:2633-2643.

25. Wilson, I. A., H. L. Niman, R. A. Houghten, A. R. Cherenson, M. L. Connolly, and R. A. Lerner. 1984. The structure of an antigenic determinant in a protein. Cell. 37:767-778.

26. Gnann, J., P. L. Schwimmbeck, J. A. Nelson, A. B. Truax, and M. B. A. Oldstone. 1987. Diagnosis of AIDS by using a 12-amino acid peptide representing an immunodominant epitope of the human immunodeficiency virus. J. Infect. Dis. 156:261-267.

27. De Lisi, C., and J. A. Berzofsky. 1985. T-cell antigenic sites tend to be amphipathic structures. Proc. Natl. Acad. Sci. USA. 82:70487052.

28. Kyte, J., and R. F. Doolittle. 1982. A simple method for displaying the hydropathic character of a protein. J. Mol. Biol. 157:105132.

29. Devereux, J., and P. Haeberli. 1986. Pepplot. In Sequence Analysis Software Package of the University of Wisconsin Genetics Computer Group. University of Wisconsin Genetics Computer Group, University of Wisconsin Biotechnology Center, Madison, WI.

30. Chou, P. Y., and G. D. Fasman. 1978. Production of the secondary structure of proteins from their amino acid sequence. $A d v$. Enzymol. 47:45-148.

31. Aoki, T., D. B. Drachman, D. M. Asher, C. J. Gibbs, Jr., S. Bahmanyar, and J. S. Wolinsky. 1985. Attempts to implicate viruses in myasthenia gravis. Neurology. 35:185-192.

32. Klavinskis, L. S., H. N. Willcox, J. E. Richmond, J. NewsomDavis. 1986. Attempted isolation of viruses from myasthenia gravis thymus. J. Neuroimmunol. 11:287-299.

33. Fujinami, R. S., and M. B. A. Oldstone. 1985. Amino acid homology between the encephalitogenic site of myelin basic protein and virus: mechanism for autoimmunity. Science (Wash. DC). 230:1043-1045.

34. Neu, N., N. R. Rose, K. W. Beisel, A. Herskowitz, G. GurriGlass, and S. Craig. 1987. Cardiac myosin induces mycarditis in genetically predisposed mice. J. Immunol. 139:3630-3636.

35. Stefansson, K., B. S. Dieperink, D. P. Richman, C. M. Gomez, and L. S. Charton. 1985. Sharing of antigenic determinants between the nicotinic acetylcholine receptor and proteins in E. coli, $P$. vulgaris, and K. pneumoniae. N. Engl. J. Med. 312:221-225.

36. Korn, I. L., and O. Abramsky. 1981. Myasthenia gravis following viral infection. Eur. J. Neurol. 21:435-439.

37. Datta, S. K., and R. S. Schwartz. 1974. Infectious (?) myasthenia. N. Engl. J. Med. 291:1304-1305.

38. Dale, J. B., and E. H. Beachey. 1985. Epitopes of streptococcal M proteins shared with cardiac myosin. J. Exp. Med. 162:583-591.

39. Krisher, K., and M. Cunningham. 1985. Myosin: a link between streptococci and heart. Science (Wash. DC). 227:413-415.

40. Kagnoff, M. F., R. K. Austin, J. J. Hubert, J. E., Bernardin, and D. D. Kasasda. 1984. Possible role for a human adenovirus in the pathogenesis of celiac disease. J. Exp. Med. 160:1544-1557. 